Research Paper

\title{
Acknowledgment of Acute Gastric Volvulus in Children: A Case Study at the Thanh Hoa Hospital of Pediatrics
}

\author{
Ta Van Tung*, Nguyen Dinh Vuong, Phung Duc Toan \\ Thanh Hoa Pediatric Hospital, Quang Trung 3, Dong Ve, Thanh Hoa, Vietnam \\ Received 19 December 2020 \\ Revised 18 March 2020; Accepted 20 April 2020
}

\begin{abstract}
Objective: Some remarks on the diagnosis and treatment of gastric volvulus.

Method: Description of cases

Results: A female, 7 years old, acute gastric volvulus was diagnosed and timely surgery.

Conclusion: Gastric volvulus is a rare emergency disease in children, so when children has had the definitive diagnosis gastric volvulus, must operate as quickly as possible.

Keywords: Gastric Volvulus
\end{abstract}

\section{Nhận xét xoắn dạ dày cấp tính ở trẻ em nhân một trường hợp tại Bệnh viện Nhi Thanh Hóa}




\title{
Tạ Văn Tùng*, Nguyễn Đình Vương, Phùng Đức Toàn
}

\author{
Bệnh viện Nhi Thanh Hóa, Quang Trung 3, Đông Vệ, Thanh Hóa, Việt Nam
}

Nhận ngày 18 tháng 11 năm 2019

Chỉnh sửa ngày 15 tháng 01 năm 2020; Chấp nhận đăng ngày 01 tháng 3 năm 2020

\section{Tóm tắt}

Mục tiêu: Nêu một số nhận xét về chẩn đoán và điều trị xoắn dạ dày.

Phương pháp nghiên cứu: Mô tả ca bệnh:

Kết quả: một trường hợp bé gái, 7 tuổi, xoắn dạ dày đã được chẩn đoán và phẫu thuật kịp thời thành công.

Kết luận: Xoắn dạ dày là bệnh lý cấp cứu hiếm gặp ở trẻ nhỏ, khi đã chẩn đoán xác định xoắn dạ dày, phải quyết định mổ kịp thời.

Tù khóa: xoắn dạ dày

\section{1. Đặt vấn đề}

Xoắn dạ dày là hiện tượng quay bất thường cuả một phần dạ dày quanh một phần dạ dày còn lại $[1,3]$. Đây là bệnh lý hiếm gặp, tỷ lệ gặp bệnh chưa được thống kê trong y văn, nhưng tần suất gặp ở người lớn nhiều hơn trẻ nhỏ $[1,4]$

Nguyên nhân gây bệnh do bất thường các dây chằng cố định dạ dày, hay thứ phát sau bệnh lý khác như thoát vị hoành, thoát vị khe thực quản... [3]

Xoắn dạ dày đã được mô tả đầu tiên bởi Berti vào năm $1866[1,4]$. Đến nay đã có nhiều bài báo về bệnh lý này $[4,8,9]$. Xoắn dạ dày được phân loại thành 2 loại: xoắn cấp tính và xoắn mạn tính. Xoắn dạ dày cấp tính là bệnh lý cấp cứu, nếu phát hiện và xử trí muộn có thể dẫn đến hoại tử dạ dày, thủng dạ dày... và có thể ảnh hưởng tính mạng bệnh nhân, tỉ lệ tử vong trong xoắn dạ dày cấp tính là cao khoảng 56\% [5] [7]. Vì tỷ lệ gặp bệnh ít nên triệu chứng lâm sàng thường trở nên khó chẩn đoán, nguy cơ đẩy

*Tác giả liên hệ.

Địa chỉ email: tavantung1956@gmail.com

https://doi.org/10.25073/ jprp.v4i2.205 bệnh lý trở nên nặng hơn hay chẩn đoán muộn trên nền một chẩn đoán khác để xử trí thường xảy ra [4], đặc biệt tại những cơ sở có tần suất bệnh nhân ngoại khoa hạn chế.

Chúng tôi báo cáo ca bệnh đã được chẩn đoán và phẫu thuật tại khoa Ngoại tổng hợp Bệnh viện Nhi Thanh Hóa, nhằm bàn luận đưa ra kinh nghiệm trong chẩn đoán, điều trị xoắn dạ dày cấp tính.

\section{Giới thiệu trường hợp bệnh}

Bệnh nhân nữ: Lê Quỳnh A , 7 tuổi, Số lưu trữ: 009239

Đia chỉ: Yên Xuân - Yên Lễ - Như Xuân- Thanh Hóa

Nhập viện: 4giờ25' ,18/3/2016

Lý do nhập viện: Đau bụng, nôn.

Bệnh sử: Trẻ xuất hiện triệu chứng nôn, đau bụng khoảng 2 ngày nay, không sốt. Bệnh viện huyện Như Xuân chuyển Bệnh viện Nhi Thanh Hóa với chẩn đoán: Tắc rụôt 4giờ 25', 18/3/2016 tình trạng nhập viện tại khoa cấp cứu:

Trẻ tỉnh, da niêm mạc hồng; Huyết động ổn định, thông khí phổi hai bên tốt. Bụng chướng vừa vùng thượng vị . 
Chẩn đoán lúc nhập viện: Tắc ruột 4giờ40', 18/3/2016 trẻ nhập khoa Ngoại tổng hợp:

Trẻ tỉnh, da niêm mạc hồng, huyết động ổn định.

Bụng chướng vừa, kích thích không dấu hiệu rắn bò, ấn hai bên hố chậu mềm, ấn vùng thượng vị trẻ kêu đau tức.

Siêu âm ổ bụng: ổ bụng không có dịch, hình ảnh quai ruột chứa nhiều hơi.

XQuang ổ bụng: không hình mức nước hơi, không hình ảnh liềm hơi, hình ảnh các quai ruột chứa nhiều hơi.

Xét nghiệm huyết học, sinh hóa bình thường.

Chẩn đoán vào khoa: TD tắc ruột/ TD Viêm dạ dày tá tràng.

Điều trị: truyền dịch bù nước điện giải (ringerlactac, glucose), thuốc chống co thắt (atropin sulfast) 5giờ30', 18/3/2016

Trẻ đau bụng tăng lên, đau cơn dữ dội, nôn khan, nôn nhiều lần.

Bụng chướng lệch về thượng vị, ấn vùng thượng vị đau tăng

Đặt sonde dạ dày thấy khó đẩy xuống, không thấy dịch ra sonde

XQuang ổ bụng tư thế đứng không chuẩn bị: Hình mức nước hơi vùng thượng vị

Chẩn đoán: Xoắn dạ dày cấp 6 giờ 18/3/2016, phẫu thuật (1giờ 45 phút sau nhập viện)

Mở bụng đường trắng giữa trên rốn vào ổ bụng thấy: dạ dày căng to ép sát vào thành bụng, đại tràng phải và đại tràng góc gan giãn to xoắn theo dạ dày, đại tràng phải và manh tràng không cố định vào thành bụng sau.
Tiến hành tháo xoắn dạ dày phối hợp với hút dịch dạ dày, kèm tháo xoắn đại tràng góc gan.

Cố định mặt trước dạ dày vào thành bụng trước sau khi đẩy hơi từ dạ dày lưu thông qua ruột xuống đến hậu môn

Cắt ruột thừa cố định manh tràng và đại tràng lên vào thành bụng sau.

Lau sạch ổ bụng. Đóng thành bụng 2 lớp.

Diễn biến sau phẫu thuật

Sau phẫu thuật tiếp tục dùng kháng sinh Ceftriaxone và Metronidazone, giảm tiết dịch vị, nuôi dưỡng qua đường tĩnh mạch, lưu sonde dạ dày. Ngày thứ thứ 5 sau mổ trẻ đại tiện được. Ngày thứ 8 sau mổ trẻ xuất viện. Hiện tại sức khỏe của cháu tốt (Hình 1, Hình 2, Hình 3).

\section{Bàn luận}

3.1. Tần suất gặp: Xoắn da dày là bệnh hiếm gặp, tần xuất gặp ở người truởng thành nhiều hơn trẻ nhỏ, tỷ lẹ gặp ở trẻ em là 10-20\% nhung thường trước 1 tuổi [3]

Trong báo cáo Ahmed H, Al-Salem ở bệnh viện Maternity and Children Hospital,Dammam, Saudi Arabia tổng kết trong 10 năm từ tháng 1 năm 1996 đến tháng 12 năm 2005 gặp 36 trẻ xoắn dạ dày cả xoắn cấp tính và mạn tính chủ yếu trong nhóm tuổi từ 1 tuần đến 2,5 năm [4].

Theo Bilal Mirza, Lubna, Afzal Sheikh khoa ngoại, bệnh viện The Children's Hospital and The Institute of Child Health, Lahore, Pakistan gặp 10 trường hợp xoắn dạ dày từ năm 2006 đến 2010 [6]. 


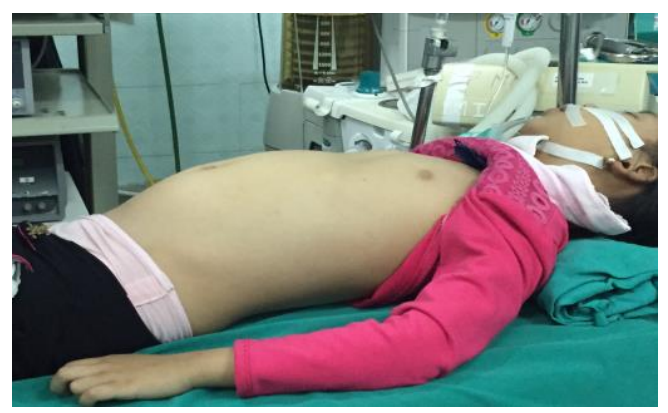

Hình 1: Bụng chứng lệch về thượng vị (Nguồn: BN: Lê Quỳnh A. MS:009239).

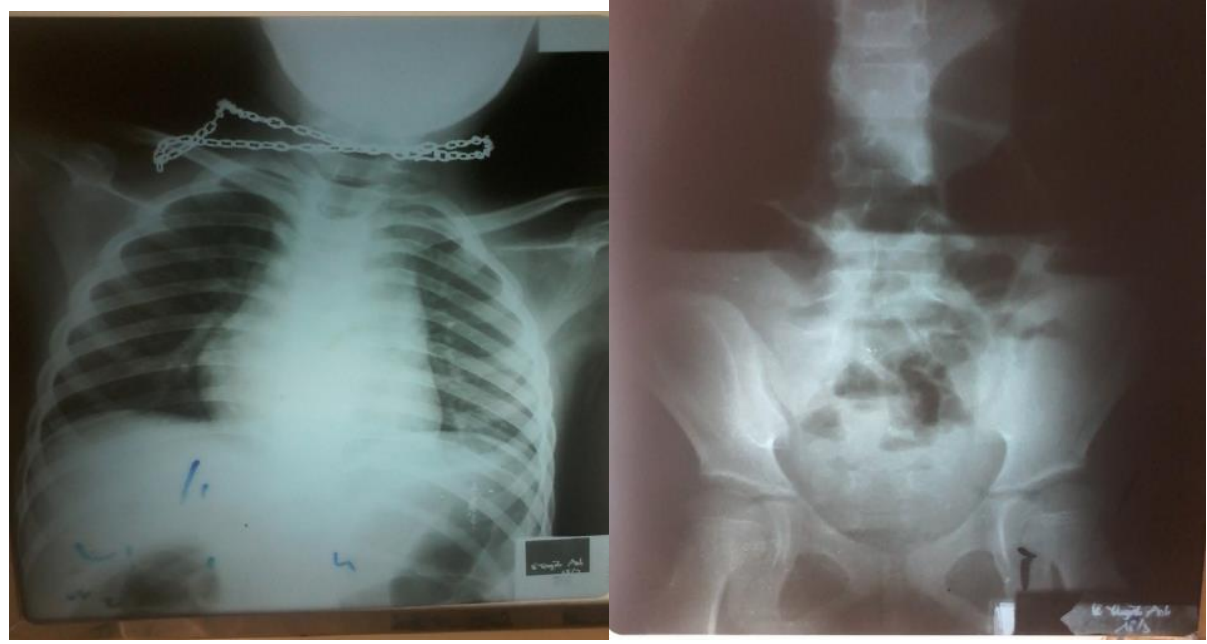

Hình 2: HA bóng hơi dạ dày căng lớn và hình mức nước mức hơi trong ổ bụng. (Nguồn: BN: Lê Quỳnh A. MS:009239)

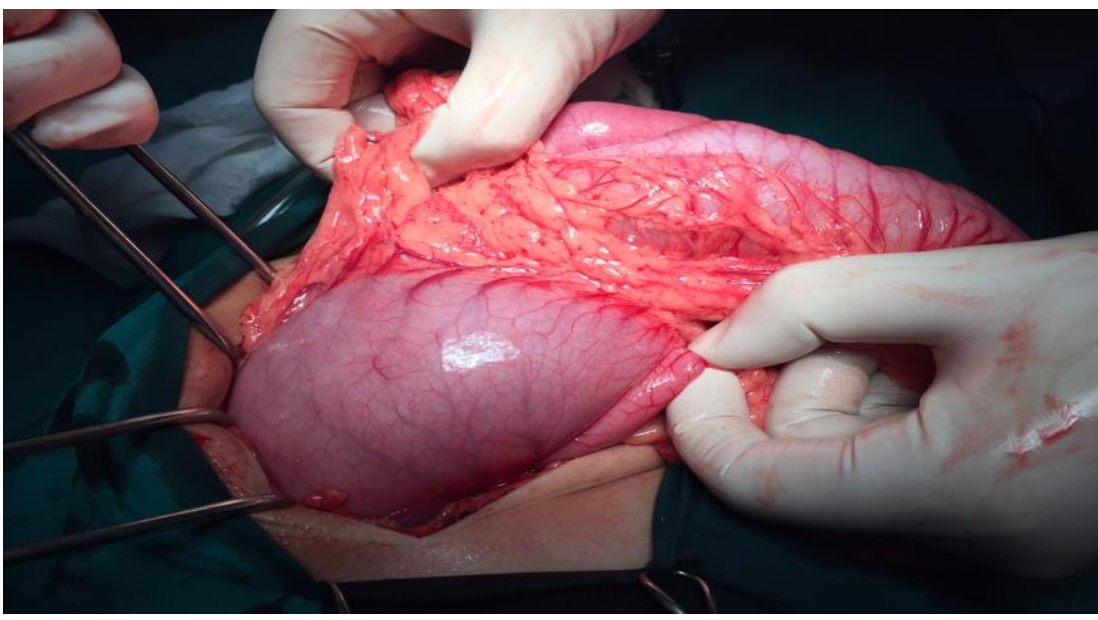

Hình 3: Dạ dày giãn, đẩy bờ cong lớn xoay về trước, đại tràng phải và đại tràng góc gan giãn di động. (Nguồn : BN: Lê Quỳnh A . MS:009239) 
Xoắn dạ dày cấp tính ở trẻ lớn gặp càng ít, vì vậy chẩn đoán càng khó khăn hơn.

Từ thời kỳ thành lập bệnh viện đến nay đây là ca xoắn dạ dày đầu tiên chúng tôi gặp ở trẻ lớn.

\subsection{Bệnh $\sinh$}

Dạ dày bình thường được cố định chắc chắn vào thực quản và các tạng lân cận nhờ các dây chằng vị-hoành, vị-tì, vị-đại tràng, vị-gan, và vị-tá tràng $[1,3]$. Dạ dày dễ bị xoắn hơn khi kết hợp với hẹp môn vị, tắc tá tràng hoặc lách di động $[1,3]$. Vì vậy khi có sự khiếm khuyết, lỏng lẻo bất thường của hệ thống dây chằng và tạng lân cận sẽ gây nên xoắn dạ dày.

Ca bệnh của chúng tôi dạ dày giãn căng to bờ cong lớn bị đẩy ra phía trước, kèm theo đại tràng phải và đại tràng góc gan căng giãn to, ruột phía dưới xẹp đều đây là thuộc kiểu xoắn theo trục tạng. Kiểm tra nguyên nhân gây xoắn thấy đại tràng phải và đại tràng góc gan không được cố định vào thành bụng sau làm cho phần đáy và bờ cong lớn của dạ dày di động nhiều gây xoắn. Kiểm tra các tạng lân cận không thấy bất thường, lách không di động, tá tràng không hẹp, các thành phần cố định dạ dày khác không thấy bất thường.

\subsection{Triệu chứng và chẩn đoán}

Xoắn dạ dày cấp tính biểu hiện bằng tam chứng cổ điển (tam chứng được Borchardt mô tả năm 1904) [1]:

- Đau vùng thượng vị kèm chướng

- Nôn mạnh và nôn khan

- Không hoặc khó đặt sonde dạ dày

Trong ca bệnh, bệnh nhân biểu hiện điển hình của tam chứng Borchardt trên lâm sàng. Kèm theo kết quả chụp XQ ổ bụng không chuẩn bị có dấu hiệu bóng hơi dạ dày dạng hình cầu đồng thời có hình mức nước mức hơi. Vì vậy chẩn đoán xác định để can thiệp phẫu thuật kịp thời, giảm tổn thương nặng nề cho bệnh nhân.

\subsection{Phuoong pháp phẫu thuật}

Chúng tôi tiến hành tháo xoắn dạ dày phối hợp với hút dịch dạ dày, kèm tháo xoắn đại tràng góc gan. Cắt ruột thừa cố định manh tràng và đại tràng lên vào thành bụng sau. Cố định mặt trước dạ dày vào thành bụng trước sau khi làm nghiệm pháp Webb bơm hơi từ dạ dày lưu thông qua ruột xuống đến hậu môn.

Theo Nguyễn Thanh Liêm, Ahmed... xoắn dạ dày cấp tính là một cấp cứu ngoại khoa cần phải can thiệp sớm, nếu chậm sẽ nguy cơ dạ dày bị hoại tử và thủng $[1,4]$. Ở ca bệnh thời gian khi chẩn đoán xác định đến khi can thiệp phẫu thuật chúng tôi mất 1 giờ $20^{\prime}$, khi phẫu thuật vào ổ bụng thấy dạ dày chưa có dấu hiệu thâm tím hoại tử, bên cạnh đó khi có dấu hiệu nghi ngờ chúng tôi tiến hành đặt sonde dạ dày sớm. Theo Nguyễn Thanh Liêm khi tháo xoắn nên chọc kim vào dạ dày để giảm áp lực làm cho tháo xoắn dễ [1]. Tuy nhiên trong quá trình tháo xoắn chúng tôi phối hợp vừa hút dịch dạ dày vừa tiến hành tháo xoắn thấy kết quả tốt. Can thiệp nội khoa trong xoắn dạ dày được đặt ra trong trường hợp xoắn dạ dày mạn tính tuy hiện nay vẫn đang còn chưa thống nhất về mức độ can thiệp. Với xoắn dạ dày cấp can thiệp ngoại khoa là can thiệp cần thiết, khi can thiệp ngoài giải phóng tình trạng xoắn của dạ dày còn có thể tìm được nguyên nhân và giải quyết nguyên nhân gây xoắn, đồng thời cố định dạ dày vào thành bụng tránh nguy cơ tái phát. Trong ca bệnh chúng tôi xác định được nguyên nhân gây xoắn là do đại tràng phải và manh tràng không được cố định vào thành bụng sau vì vậy một trong những dây chằng neo giữ dạ dày là dây chằng vị đại tràng không tác dụng gây xoắn dạ dày. Để giải quyết nguyên nhân và tránh tái phát 
chúng tôi đã tiến hành cố định manh tràng và đại tràng phải vào thành bụng sau và cố định dạ dày vào thành bụng trước.

\section{Kết luận}

Xoắn dạ dày ở trẻ em là bệnh hiếm gặp, tuy nhiên khi trẻ có dấu hiệu đau thượng vị, nôn khan, bụng chướng lệch về phía thượng vị, kèm theo đặt sonde dẫn lưu dạ dày khó, XQ có hình mức nước hơi kèm theo bóng hơi dạ dày giãn hình cầu ta nên nghĩ đến xoắn dạ dày. Nhân trường hợp ca bệnh đã được chẩn đoán và phẫu thuật kịp thời đạt kết quả tốt, chúng tôi hy vọng cung cấp, nhắc lại phần nào những thông tin hữu ích trong chẩn đoán và điều trị nhằm giảm những tổn thương nặng nề cho bệnh nhân.

\section{Tài liệu tham khảo}

[1] Nguyen Thanh Liem. Children gastrointestinal surgery. Gastric volvulus 2000: Medical Publishing House. (76-79) (in Vietnamese)
[2] Trinh Van Minh, Human anatomy. Vol. 2. 2007: Hanoi Publishing House. 291. (in Vietnamese)

[3] Ahmed H. Al-Salem, An Illustrated Guide to Pediatric Surgery 2014: Springer.

[4] Ahmed H. Al-Salem, Acute and chronic gastric volvulus in infants and children: who should be treated surgically? Pediatr Surg Int 2007. 23.

[5] Bang Chau and Susan Dufel, Gastric volvulus. Emerg Med J 2007;24:446-447.

[6] Bilal Mirza, Lubna Ijaz, and A. Sheikh., Gastric volvulus in children: our experience. Indian J Gastroenterol 2012;31:258-262.

[7] Cosimo Mazzei, et al., Partial gastric necrosis due to acute gastric volvulus secondary to agenesis of the gastrocolic ligament. International Journal of Colorectal Disease 2013;28:1315-1316.

[8] Rantomalala HY, et al., A case of acute gastricvolvulus in a child. Arch Pediatr 2005; 12:1726-1728.

[9]Tillman BW1, et al., Acute gastric volvulus in a six-year-old: a case report and review of the literature. J Emerg Med 2014;46: 191-196. 